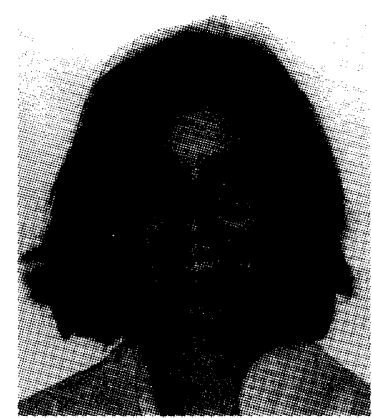

Joanna Sax

Joanna Sax focuses her legal research on policy issues surrounding health law and biomedical research. She received a Ph.D. in Cell and Molecular Biology from the University of Pennsylvania School of Medicine in 2003. In 2006, she received a J.D. from the University of Pennsylvania Law School. Joanna Sax is a first year associate at a law firm in San Francisco, California. 



\title{
Reforming FDA Policy for Pediatric Testing: Challenges AND Changes In the WaKe of Studies USING ANTIDEPRESSANT DRUGS
}

\author{
Joanna K. Sax * \\ TABLE OF CONTENTS
}

I. INTRODUCTION

II. HISTORICAL TREATMENT OF CHILDREN IN DRUG TESTING IMPACTS REGULATORY REFORM.

III. LEGISLATIVE HISTORY OF THE ACTS DESIGNED TO PROTECT CHILDREN IN THE TESTING AND USE OF FDA APPROVED DRUGS

A. Patent Exclusivity for Voluntarily Conducting

Pediatric Trials 66

B. The FDA Required Pediatric Testing Under the 1998 Final Rule

C. Pediatric Testing of Both Patented and Off-Patent Drugs is Permitted Under the Best Pharmaceuticals for Children Act

D. The Pediatric Research Equity Act Essentially Codified the 1998 Final Rule.

IV. THE ANTIDEPRESSANT STORY IS A MODEL FOR THE

DEFICIENCIES IN THE CURRENT LEGISLATION

A. The Forest Laboratories Clinical Studies Demonstrate Conflicting Clinical Results.

B. Anecdotal Reports Regarding Selective Serotonin Re-Uptake Inhibitors Caused the British Medical Health Regulatory Agency to Ban the Use of This Class of Antidepressant Drugs in Children.

C. The Eli Lilly Clinical Studies Showed that the FDA and Researchers Must be Attentive When Taking Adolescents Off Antidepressants

D. Committee Hearings Addressed Antidepressant

Clinical Studies in Pediatric Populations

V. POLICY RECOMMENDATIONS TO ADDRESS THE DIFFICULTIES ASSOCIATED WITH PEDIATRIC STUDIES

\footnotetext{
* J.D., 2006, University of Pennsylvania Law School, Philadelphia, Pennsylvania; Ph.D., 2003, Cell and Molecular Biology, University of Pennsylvania School of Medicine, Philadelphia, Pennsylvania; B.S., 1997, Zoology, University of Wisconsin, Madison, Wisconsin. The author wishes to thank Professor Theodore Ruger for invaluable comments and criticisms.
} 
A. Public Databases That Disclose Medical Device and Drug Tests by Reporting Inconclusive or Negative Clinical Trials ..... 76

B. Changes Should Be Made to the Exclusivity Provision.............. 78

C. The New Policy Should Address Labeling Changes.................. 80

D. The FDA Should Implement Additional Post-Approval Surveillance Mechanisms .......................................................8 82

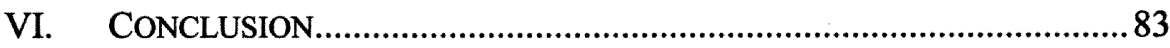

\section{INTRODUCTION}

Many physicians "dose down" a drug approved by the Food and Drug Administration ("FDA") when prescribing it for children to account for their lower body weight. Children, however, may react differently to drugs than adults for a variety of reasons including kidney and liver development. The practice of "dosing down" may not always account for these physiological differences. ${ }^{1}$ Indeed, some physicians may worry about adverse side effects when "dosing down" and may opt to prescribe less effective medication that is known not to have serious adverse effects in children. The dilemma presents physicians with a choice, on the one hand, to prescribe a potentially more effective medication and risk adverse side effects because it has not been tested in pediatric populations, or, on the other hand, to use an older and perhaps less effective drug. Recognizing the problem of safe and effective drug use in children, Congress and the Food and Drug Administration (FDA) have enacted statutes and regulations respectively, which only begin to address the plethora of problems associated with prescribing drugs to pediatric populations.

It was not until the past decade that Congress significantly recognized the need for drug testing in pediatric populations. The first in the line of these legislative schemes was the Food and Drug Administration Modernization Act of 1997 ("FDAMA"), which included a pediatric drug exclusivity provision to encourage drug testing in children. ${ }^{2}$ Although drug companies were not required to conduct clinical trials in children, the FDAMA encouraged such drug testing by offering a six-month patent extension period. ${ }^{3}$

With the impending 2002 sunset provision of the FDAMA, Congress passed the Best Pharmaceuticals for Children Act ("BPCA"). ' The BPCA also

1 Jerome Groopman, The Pediatric Gap: Why Have Most Medications Never Been Properly Tested on Kids?, THE NEW YORKER, Jan. 10, 2005, at 32, 32-35 (describing the myriad of problems associated with administering drugs to pediatric patients).

2 Food and Drug Administration Modernization Act of 1997, Pub. L. No. 105-115, § 111, 111 Stat. 2296, 2305-09 (1997) (codified as amended at 21 U.S.C. § 355a), amended by Best Pharmaceuticals for Children Act, Pub. L. No. 107-109, 115 Stat. 1408 (2002) (codified in scattered sections of 21 U.S.C. and 42 U.S.C.).

321 U.S.C. $\S 355 \mathrm{a}$ (b) (2000 \& Supp. IV 2004).

${ }^{4}$ Best Pharmaceuticals for Children Act, Pub. L. No. 107-109, 115 Stat. 1408 (2002) (codified in scattered sections of 21 U.S.C. and 42 U.S.C.). 
grants the six-month patent exclusivity extension but goes one step further. ${ }^{5}$ If the FDA determines more information is needed about a particular drug, it can refer the drug to the National Institutes of Health ("NIH") and authorize the NIH to collect funds and award research grants to third parties to test the drug. ${ }^{6}$ The BPCA also establishes a public fund that the FDA can use to pay a third party directly to conduct the appropriate tests. ${ }^{7}$ The results of these tests must then be reported back to the FDA. ${ }^{8}$ The BPCA, however, sunsets in $2007 .^{9}$

On the heels of the FDAMA, the FDA promulgated the 1998 "Pediatric Rule," which allowed the FDA to require pediatric testing on already marketed drugs and require pediatric testing and labeling of new drugs. ${ }^{10}$ Pharmaceutical companies, however, could request a full or partial waiver of this requirement. ${ }^{11}$ In October 2002, a United States District Court for the District of Columbia struck down the 1998 Pediatric Rule as incompatible with the BPCA and exceeding the authority of the FDA under the Food Drug and Cosmetic Act ("FDCA"). 12 Shortly after the court's decision, Congress passed the Pediatric Research Equity Act of 2003 ("PREA"). ${ }^{13}$ The PREA codified the "Pediatric Rule," and it will sunset in $2007 .^{14}$

The importance of regulated pediatric clinical trials is underscored by medical discoveries that adults and children react differently to certain medications. One malady present in both the pediatric and adult population is depression. Although exact biological differences between adult and pediatric depression are unclear, some experts believe they are not identical and therefore antidepressant medications may work differently in a developing brain. ${ }^{15}$ For example, in 2003, the British government concluded that Seroxat (known as

521 U.S.C. § 355a(b) (Supp. IV 2004).

642 U.S.C. $\S 284 \mathrm{~m}(\mathrm{a})-(\mathrm{b})$ (Supp. III 2003).

7 Id. $\S \S 284 \mathrm{~m}(\mathrm{c})(1),(\mathrm{d})$.

8 Id. $\S 284 \mathrm{~m}(\mathrm{c})(6)(\mathrm{A})$.

921 U.S.C. $§ 355 a(n)$ (Supp. IV 2004) (sunset date is Oct. 1, 2007).

10 Regulations Requiring Manufacturers to Assess the Safety and Effectiveness of New Drugs and Biological Products in Pediatric Patients, 63 Fed. Reg. 66,632, 66,639 (Dec. 2, 1998) (to be codified at 21 C.F.R. pts. 201, 312,314, and 601).

1121 C.F.R. $\$ \S 314.55(c)(1)-(4), 601.27(c)(1)-(4)$ (2006). See also Ass'n of Am., Physicians \& Surgeons, Inc. v. FDA, 226 F. Supp. 2d 204, 208 (D.D.C. 2002).

${ }^{12}$ Ass' $n$ of Am., Physicians \& Surgeons, Inc., 226 F. Supp. 2d at 220-21 (describing that the "Pediatric Rule" was neither accepted nor rejected by Congress when adopting the BPCA and that the "Pediatric Rule" exceeds the FDA's statutory authority).

13 Pediatric Research Equity Act of 2003, Pub. L. No. 108-155, 117 Stat. 1936 (codified as amended at 21 U.S.C. § 355c (Supp. IV 2004)).

${ }^{14} \mathrm{Id}$; Groopman, supra note 1, at 35 ("In 2003, Congress passed legislation that codified what is known as the Pediatric Rule. ... [T] he reforms include a 'sunset clause' ... (This clause was added as a result of pressure from drug companies and groups that oppose government regulation.)").

${ }_{15}$ Groopman, supra note 1, at 34 ("Although the precise biological differences between adult depression and childhood depression are not yet known, there is reason to believe that the maladies are not identical, and that antidepressants may work differently on a developing brain."). 
Paxil in the United States) should not be prescribed to children because of increased suicidal behavior and withdrawal symptoms. ${ }^{16}$ The FDA followed suit -- but not until ten months later. ${ }^{17}$

Eli Lilly recently received bad press when college student Traci Johnson committed suicide after moving from the antidepressant Cymbalta to a placebo during a clinical trial for treatment of depression, thus highlighting the potential problem of withdrawal from a drug. ${ }^{18}$ Although the FDA cleared Eli Lilly of wrongdoing, ${ }^{19}$ this tragic episode highlights some problems associated with pediatric testing. Indeed, at about the same time, the FDA reported the results of a 2004 study indicating that twice as many children taking antidepressants had suicidal behavior compared to children taking placebos. ${ }^{20}$ This study exemplifies the need for heightened monitoring of children in pediatric studies -because pediatric populations may react differently than adult populations.

Despite both FDA and congressional attempts to address the problems of prescription drug use in children, several deficiencies and loopholes exist. Thus, conducting clinical trials in this vulnerable population must be highly regulated. Part II briefly introduces that the historical treatment of children impacts regulatory reform. Part III will explain the evolution of regulatory and legislative approaches to pediatric drug testing, highlighting how each new legislative program contained special precautions to widen the number of drugs tested in children and also protected children as participants in clinical trials. Part IV, however, demonstrates how these statutory and regulatory provisions have failed to address the use of antidepressant mediation in pediatric patients. In response to learning that pediatric populations may be at risk when taking antidepressant mediation, Congress held hearings to determine whether the FDA and drug manufacturers were conducting and publicizing the results of positive, negative, and inconclusive clinical trials. As the sunset date of the current programs approaches, new policy changes are proposed in Part $\mathrm{V}$ for consideration as the FDA moves forward. While the recent legislative schemes offer some protection to children as clinical subjects, they do not provide enough protection once the drug is on the market. Legislative and policy reforms might include the following: public disclosure of all clinical trials,

16 Id. at 35 (describing that in the $1980 \mathrm{~s}, 1990 \mathrm{~s}$, and $2000 \mathrm{~s}$, the British government monitored reports of selective serotonin re-uptake inhibitors and ultimately concluded they were not safe for use in children).

17 E.g., id.

18 Id. at 34 ("Indeed, Eli Lilly and Company recently received a tremendous amount of bad press when Traci Johnson, an Indiana college student, committed suicide during a clinical trial of Cymbalta, an antidepressant.").

19 E.g., id.; U.S. Finds No Link Between a Suicide and a Lilly Drug, N.Y. TIMES, Aug. 13,2004 , at C4.

${ }^{20}$ Groopman, supra note 1, at 34 ("Johnson's death occurred at the same time that the F.D.A. was analyzing a large set of data compiled from multiple clinical trials. The results, which were released in October, indicated that twice as many children taking antidepressants in clinical trials considered or attempted suicide as children taking placebos."). 
changes in the exclusivity provision, labeling changes, and post-approval drug surveillance.

\section{HISTORICAL TREATMENT OF CHILDREN IN DRUG TESTING IMPACTS REGULATORY REFORM}

Historically, children were used as subjects in medical experiments. ${ }^{21} \mathrm{Un}$ til the later part of the twentieth century, the government made few efforts to regulate pediatric testing, and children were often forced to participate in dangerous tests. ${ }^{22}$ In addition, the testing among pediatric populations usually focused on understanding a disease, rather than testing new drugs that could be used to treat it.

Children need protection from medical mistreatment. This set of ethical concerns, regarding the protection of children entering a clinical trial, includes issues such as consent, protection of disabled children, and associated health risks. A thorough discussion of the ethical dilemmas regarding children in clinical trials is beyond the scope of this Article, but a large body of law review articles specifically addresses this difficult and critical area. ${ }^{23}$

Clinical trials for safe and effective treatments of childhood ailments need to be conducted. This Article focuses on this set of issues that concerns the testing of pediatric drugs to determine whether they are safe and effective for pediatric populations. As described above, because relatively few drugs are tested on pediatric populations, doctors tend to "dose down" adult dosages to account for the lower body weight in children. Children, however, have physiological differences that may cause a drug to metabolize differently. Government regulations aimed at promoting and even requiring drug testing in children are necessary to ensure the safe and effective use of drugs in pediatric populations. Described below are the current legislative and regulatory schemes addressing such drug experimentation in pediatric populations. Although these schemes are a good starting point to address the problems of drug testing in children, they do not go far enough.

21 See generally Susan E. Lederer \& Michael A. Grodin, Historical Overview: Pediatric Experimentation, in CHILDREN AS RESEARCH SUBJECTS: SCIENCE, ETHICS, AND LAW 3, 3-20 (Michael A. Grodin \& Leonard H. Glantz eds., 1994).

22 Lauren Hammer Breslow, Note, The Best Pharmaceuticals for Children Act of 2002. The Rise of the Voluntary Incentive Structure and Congressional Refusal to Require Pediatric Testing, 40 HARV. J. ON LEGIS. 133, 135-41 (2003); Lederer \& Grodin, supra note 21 (describing children as research subjects in eighteenth, nineteenth, and twentieth centuries); Leonard $\mathrm{H}$. Glantz, The Law of Human Experimentation with Children, in CHILDREN AS RESEARCH SUBJECTS: SCIENCE, ETHICS, AND LAW 103, 103 (Michael A. Grodin \& Leonard H. Glantz eds., 1994) [hereinafter Glantz, The Law of Human Experimentation with Children] (explaining that until the last half of the twentieth century virtually no regulations governed pediatric testing).

${ }^{23}$ See, e.g., Carrie Fisher \& Thomas G. Keens, Participation of Children in Research, 26 WHITTIER L. REV. 823 (2005); Glantz, The Law of Human Experimentation with Children, supra note 22; Leonard H. Glantz, Research with Children, 24 AM. J.L. \& MED. 213 (1998). 


\section{LEGISLATIVE HISTORY OF THE ACTS DESIGNED TO PROTECT CHILDREN IN THE TESTING AND USE OF FDA APPROVED DRUGS}

In 1997, Congress enacted the FDAMA, which, although affecting numerous FDA regulations, also has been the first congressional action to address specifically the problems of testing new drugs in children. ${ }^{24}$ The FDAMA was followed by key regulations and subsequent congressional acts focusing on the emerging recognition of the need for pediatric drug testing.

\section{A. Patent Exclusivity for Voluntarily Conducting Pediatric Trials}

The FDAMA significantly changed the regulatory scheme for pediatric testing. Most notably, it granted pharmaceutical companies a six-month patent extension in exchange for conducting pediatric trials of their drug. ${ }^{25}$ The patent exclusivity provision applied only to future or existing patented drugs. ${ }^{26}$ That is, if a drug company was outside the exclusive period provided by the patent, pediatric clinical trials for that particular drug would not give the pharmaceutical company an exclusive six-month market.

The market exclusivity approach is similar to the Hatch-Waxman Act, which allows patent extensions for drugs in order to compensate for the time the drug is moving through the regulatory process. ${ }^{27}$ Prior to the HatchWaxman Act, a pharmaceutical company would receive a patent for its drug before completing the FDA regulatory approval process but could not market the drug until the FDA approved it. Therefore, the company would not be able to enjoy the market exclusivity granted by the patent while the drug was in the regulatory pipeline. The Hatch-Waxman Act allows a patent extension tacked on to the end of a drug's patent term to compensate for the delay experienced during the approval process. ${ }^{28}$

Providing patent extensions for voluntary pediatric drug testing has been described as a "carrot and stick" approach. ${ }^{29}$ The "carrot" is the six-month

${ }^{24}$ See generally Food and Drug Modernization Act of 1997, Pub. L. No. 105-115, § 505A, 111 Stat. 2296, 2305-09 (1997) (codified as amended at 21 U.S.C. $\S 355 a$ ). While the FDA attempted to regulate pediatric research studies through enactment of rules, the FDAMA of 1997 is the first congressional act to specifically address pediatric drug research. Id. See Christopher-Paul Milne, Exploring the Frontiers of Law and Science: FDAMA's Pediatric Studies Incentive, 57 FoOD \& DRUG L.J. 491, 491 (2002) (describing the push for the Better Pharmaceuticals for Children Act and its incorporation into the FDAMA); Breslow, supra note 22, at 15155 (describing steps taken by the FDA to regulate pediatric testing but also noting that Congress enacted the FDAMA which overhauled the FDCA).

${ }_{25} 21$ U.S.C. § 355a(b) (2000 \& Supp. IV 2004); see Breslow, supra note 22, at 155-57 (discussing the market exclusivity provision).

2621 U.S.C. $\S 355 \mathrm{a}$ (b) (applying to both new drugs and already-marketed drugs).

2721 U.S.C. § 355 (2000 \& Supp. III 2003); 35 U.S.C. § 156(a)(4) (2000).

2821 U.S.C. $\$ 355$.

29 Kurt R. Karst, Comment, Pediatric Testing of Prescription Drugs: The Food and Drug Administration's Carrot and Stick for the Pharmaceutical Industry, 49 AM. U.L. REV. 
market exclusivity granted to pharmaceutical companies, beyond the granted patent time period, that conduct pediatric clinical trials voluntarily. ${ }^{30}$ This market exclusivity provision could potentially allow pharmaceutical companies to make millions of dollars for heavily prescribed drugs. The "stick" is the FDA rule that requires companies to assess the safety and effectiveness of the drug in pediatric populations. $^{31}$

At that time, a second provision of the FDAMA stated that the Secretary is "to develop a list of drugs for which additional pediatric information may be beneficial." ${ }^{\text {"32 }}$ Under this provision, the Secretary is to publish a prioritized list of FDA approved drugs that are deemed to need clinical testing in pediatric patients. ${ }^{33}$ This list is to be updated annually. ${ }^{34}$ Another provision applied to conducting pediatric studies. ${ }^{35}$ This provision discusses the protocols and time frame for the requirements of pediatric clinical studies. ${ }^{36}$ The BPCA, enacted in 2002, addressed and changed section 111 and is discussed in greater detail below.

\section{B. The FDA Required Pediatric Testing Under the 1998 Final Rule}

The FDA also proceeded on its own course to regulate drug testing in pediatric patients and promulgated the 1998 Final Rule. ${ }^{37}$ The 1998 Final Rule acknowledged the market exclusivity provision in the FDAMA. The FDA rule, however, went beyond the voluntary pediatric testing requirement in the FDAMA by allowing the FDA to require pediatric testing of already approved and marketed drugs and to favor pediatric testing in new drugs. ${ }^{38}$ In compiling the Pediatric List, the FDA included all drugs that are approved for use in

739, 739, 743-44 (2000) (describing the "carrot and stick" approach).

${ }^{30}$ Karst, supra note 29, at 743-44; see Breslow, supra note 22, at 155 (describing the six-month patent extension as a "financial boom for manufacturers").

31 Karst, supra note 29, at 744; cf. Christopher-Paul Milne, supra note 24, at 495 ("Seemingly taking their cue from the stance of the Executive Office, some members of Congress accused FDA of playing 'hide the carrot' by requesting only a small number of pediatric trials under FDAMA. At the same time, the agency ostentatiously waved the stick by reportedly stating that, if the opportunity offered by the FDAMA incentives went unanswered, FDA would 'consider exercising its authority to require studies."').

32 Food and Drug Administration Modernization Act of 1997, Pub. L. No. 105-115, § 505A(b), 111 Stat. 2296, 2306 (1997) (codified as amended at 21 U.S.C. § 355a); see Breslow, supra note 22, at 156.

${ }^{33}$ Food and Drug Administration Modernization Act of $1997 \S 505 \mathrm{~A}(\mathrm{~b})$.

34 Id.

${ }^{35} I d . \S 505 \mathrm{~A}(\mathrm{~d}), 111$ Stat. at 2307.

${ }^{36} I d . \S 505 \mathrm{~A}(\mathrm{~d})(2)$.

37 Regulations Requiring Manufacturers to Assess the Safety and Effectiveness of New Drugs and Biological Products in Pediatric Patients, 63 Fed. Reg. 66,632, 66,633 (Dec. 2, 1998); see generally Breslow, supra note 22, at 159-63 (discussing the Final Rule).

${ }_{38}$ Regulations Requiring Manufacturers to Assess the Safety and Effectiveness of New Drugs and Biological Products in Pediatric Patients, 63 Fed. Reg. 66,632, 66,634 (Dec. 2, 1998). 
adults for a disease or condition that occurs in children. ${ }^{39}$ The FDA also requires new drugs that had a high probability of use in pediatric populations to undergo pediatric testing. ${ }^{40}$

Under the 1998 Final Rule, pharmaceutical companies could request a waiver for pediatric testing. ${ }^{41}$ To receive a waiver, the FDA must be satisfied that (1) the drug did not provide a therapeutic benefit over the existing treatment and (2) the drug would not be used in a substantial number of pediatric patients. $^{42}$ If a company did not receive a waiver, the FDA could file an action in federal court seeking an injunction based on the manufacturer's noncompliance. ${ }^{43}$ The court could then require the manufacturer to assess the safety and effectiveness of the drug in pediatric populations. ${ }^{44}$

In addition, the FDA separated the pediatric population into the following arbitrary age groups: neonates (up to one month old); infants (one month to two years old); children (two to twelve years old); and adolescents (twelve to sixteen years old). ${ }^{45}$ These age ranges, however, do not necessarily account for physiological differences. Moreover, older teenagers and young adults may still undergo developmental changes. Issues regarding these age groups are further discussed below.

\section{Pediatric Testing of Both Patented and Off-Patent Drugs is Permitted Under the Best Pharmaceuticals for Children Act}

When enacted, Section 111 of the FDAMA was set to sunset in 2002. In 2002, however, Congress enacted the Best Pharmaceuticals for Children Act ("BPCA"), ${ }^{46}$ which includes the market-exclusivity provision in the FDAMA

39 FDA Docket No. 98 N-0056, List of Drugs for Which Additional Pediatric Information May Produce Health Benefits in the Pediatric Population 1, 1-3 (May 20, 1998); see Michael S. Labson, Pediatric Priorities: Legislative and Regulatory Initiatives to Expand Research on the Use of Medicines in Pediatric Patients, 6 J. HEALTH CARE L. \& POL'Y 34, 47 (2002) (describing the Pediatric List).

40 See Labson, supra note 39, at 48 (2002).

41 Regulations Requiring Manufacturers to Assess the Safety and Effectiveness of New Drugs and Biological Products in Pediatric Patients, 63 Fed. Reg. 66,632 (Dec. 2, 1998) (codified at 21 C.F.R. pts. 201, 312, 314, and 601 (2006)).

4221 C.F.R. $\S \S 314.55(c)(2)(i), 601.27(c)(2)(i)(2002)$. See Labson, supra note 39, at 54 (describing the waiver provision).

43 Regulations Requiring Manufacturers to Assess the Safety and Effectiveness of New Drugs and Biological Products in Pediatric Patients, 63 Fed. Reg. 66, 632, 66,636 (Dec. 2, 1998); see Labson, supra note 39, at 56 (describing enforcement).

44 See 21 C.F.R. $\$ \S 201.23,601.27$ (2006) (requiring manufacturers to assess the safety and effectiveness of new drugs and biological products in pediatric patients). See also Labson, supra note 39, at 56 (describing the enforcement mechanism).

45 William J. Rodriguez, Sci. Dir. for Pediatrics, FDA, CDER's Experience: What We Have Learned From the Pediatric Initiative (Feb. 20, 2002), available at http://www.fda.gov/cder/pediatric/presentation/ped_init_rodriguez/sld024.htm(Microsoft Office PowerPoint Slide No. 24).

46 Best Pharmaceuticals for Children Act, Pub. L. No. 107-109, 115 Stat. 1408 (2002) 
and also addresses some criticisms of the FDAMA. ${ }^{47}$ Unlike the FDAMA, the BPCA addresses the testing of both on-patent and off-patent drugs. Under the BPCA, the NIH, in collaboration with the FDA, develops lists of drugs that need additional studies to assess the safety and effectiveness in pediatric populations. ${ }^{48}$ The NIH considers the following criteria to determine whether pediatric testing is needed: "(1) availability of information concerning the safe and effective use of the drug in the pediatric population; (2) whether additional information is needed; (3) whether new pediatric studies concerning the drug may produce health benefits in pediatric population; and (4) whether reformation of the drug is necessary." 49 Once the list is compiled, the FDA sends a written request to the manufacturer of each drug to request the pediatric studies. ${ }^{50}$ If the FDA does not receive a response from the manufacturer within thirty days, then the FDA will publish a request for third parties, who themselves meet particularized criteria for conducting pediatric trials, to conduct the studies. ${ }^{51}$

Once the pediatric studies are conducted, either the manufacturer or the third party submits a report that includes all data generated in the study. ${ }^{52}$ The FDA then reviews the report and begins a negotiation process with the manufacturer regarding labeling changes. ${ }^{53}$ If the manufacturer does not agree to a labeling change, the labeling request is referred to the Pediatric Advisory Committee to review the information and make a recommendation regarding the appropriate labeling changes, if any. ${ }^{54}$ The FDA then contacts the manufacturer with the committee's request. ${ }^{55}$ If the manufacturer does not comply within thirty days, the FDA may deem the drug misbranded and bring an enforcement action in federal court. ${ }^{56}$

The BPCA also addressed many of the ethical dilemmas involved with conducting pediatric research. First, the BPCA establishes the Office of Pediatric Therapeutics within the FDA to coordinate and facilitate activities related to pediatric issues. ${ }^{57}$ Second, the BPCA establishes a procedure for contracting with the Institute of Medicine ("IOM") to review pediatric studies. ${ }^{58}$ The IOM

(codified as amended in scattered sections of 21 U.S.C. and 42 U.S.C.).

4742 U.S.C. $\$ 284 \mathrm{~m}$ (a) (2000 \& Supp. III 2003) (clarifying the application of the Pediatric Exclusivity provision under section 505A of the Federal Food, Drug, and Cosmetic Act); see also Breslow, supra note 22, at 173-74 (describing the BPCA as "a greatly matured successor to the original pediatric exclusivity provision of the FDAMA.").

48 Program for Pediatric Studies of Drugs, 42 U.S.C. $\$ 284 \mathrm{~m}$ (a) (Supp. III 2003); see Breslow, supra note 22, at 174-77 (describing the Program for Pediatric Studies of Drugs).

${ }_{49}^{4} 42$ U.S.C. $\$ 284 \mathrm{~m}(\mathrm{a})(2)$.

${ }^{50}$ Id. $\S 284 \mathrm{~m}(\mathrm{~b})(\mathrm{c})$.

51 See id. $\$ 284 \mathrm{~m}(\mathrm{c})(2)$.

52 See id. $\S 284 \mathrm{~m}(\mathrm{c})(6)(\mathrm{A})$.

${ }^{53}$ See id. $\$ 284 \mathrm{~m}(\mathrm{c})(7)$.

54 See id. $\S 284 \mathrm{~m}(\mathrm{c})(8)$.

55 Id. $\S 284 \mathrm{~m}(\mathrm{c})(9)$.

${ }^{56}$ See id. $\$ \S 284 \mathrm{~m}(\mathrm{c})(10)-(11)$.

5721 U.S.C. § 393a(a)-(b) (Supp. IV 2004); see Breslow, supra note 22, at 178-79 (describing "Structural Administrative Changes").

58 Best Pharmaceuticals for Children Act, Pub. L. No. 107-109, 115 Stat. 1416 (2002) 
is to review numerous areas including assent, informed consent, benefits and risk, "minimal risk," and the role of the institutional review board in conducting the trial. ${ }^{59}$ The BPCA also contains an October 1, 2007, sunset clause. ${ }^{60}$

With the enactment of the BPCA, the Bush administration suspended the 1998 Final Rule in May 2002. ${ }^{61}$ In response, the Department of Health and Human Services ("HHS") announced the BPCA and the 1998 Final Rule could coexist but asked for public comment regarding what steps to take for the FDA to accommodate the BPCA. ${ }^{62}$ The common ground HHS asked for never came to fruition because, in 2002, the District Court for the District of Columbia held the 1998 Final Rule "[exceeded] the FDA's statutory authority and [was] therefore invalid. ${ }^{, 63}$

\section{The Pediatric Research Equity Act Essentially Codified the 1998 Final Rule}

In response to the district court's decision, in 2003 Congress amended the FDCA by enacting the Pediatric Research Equity Act ("PREA"). ${ }^{64}$ The PREA essentially codifies the 1998 Final Rule and specifically grants the FDA the authority to require pediatric testing of new and already approved drugs. ${ }^{65}$

For new drug applications, the FDA has the authority to grant manufacturers either a full or partial waiver for pediatric testing. A full waiver for new drugs is allowed in the following circumstances: (1) when a small patient population makes studies practically impossible; (2) when evidence suggests the drug will be ineffective or unsafe for all pediatric ages; (3) when the drug does not represent a meaningful benefit over existing therapies; or (4) when the drug will not be used in a substantial number of pediatric patients. ${ }^{66} \mathrm{~A}$ partial waiver for new drugs may be granted for particular age groups for the same reasons as described for granting a full waiver, but granting a partial waiver also requires the manufacturer to show that reasonable attempts to produce a pediatric formu-

(codified at 42 USC $\S 289$ note(a), note(b)); 42 U.S.C. $\S 289$ note(a) (Supp. III 2003).

5942 U.S.C. $\$ 289$ note(b).

6021 U.S.C. § 355a(n) (Supp. IV 2004).

61 Breslow, supra note 22, at 185 ("[I]n May 2002, the Bush administration decided to suspend the rule in light of the BPCA's comprehensive structure.").

${ }^{62}$ Id. ("HHS announced that the BPCA and the 1998 final rule could coexist, but also asked for public comment on 'what additional steps [the FDA could] take to assure adequate study of drugs in children in light of the BPCA.").

${ }^{63}$ Ass'n of Am., Physicians \& Surgeons, Inc. v. FDA, 226 F. Supp. 2d 204, 222 (D.D.C. 2002).

${ }^{64}$ Pediatric Research Equity Act of 2003, Pub. L. No. 108-155, 117 Stat. 1936 (codified as amended at 21 U.S.C. $\S 355$ c (Supp. IV 2004)).

6521 U.S.C. $\$ 355 \mathrm{c}(\mathrm{a})$-(b) (Supp. IV 2004); Groopman, supra note 1, at 35 ("In 2003, Congress passed legislation that codified what is known as the Pediatric Rule. A drug company working on a new treatment for a disease that affects both adults and children is now required to conduct pediatric studies.").

${ }_{66} 21$ U.S.C. $\S 355 \mathrm{c}(\mathrm{a})(4)(\mathrm{A})$. 
lation for a particular age group have failed. ${ }^{67}$

For already approved drugs, the PREA grants the FDA authority to require pediatric studies if the drug is used in a substantial number of pediatric patients for uses indicated on the label, the absence of pediatric labeling poses significant risks, and data suggest the drug will represent a meaningful therapeutic benefit over existing therapies. ${ }^{68}$ The FDA can grant a full waiver for pediatric studies if the studies are practically impossible to complete or there is strong evidence the drug would be unsafe or ineffective in all pediatric populations. $^{69}$ A partial waiver for particular age groups for already approved drugs may be granted for the same reasons as a full waiver. ${ }^{70}$ In addition, a partial waiver for a particular age group will be granted if the FDA determines four criteria: (1) the drug will not represent a meaningful therapeutic benefit over existing treatment; (2) the drug is not likely to be used in a substantial number of pediatric patients in a particular age group; (3) the absence of labeling does not pose a significant threat; and (4) the manufacturer can demonstrate that reasonable attempts to produce a formula for that age group have failed. ${ }^{71}$ The drug label must indicate whether a waiver has been granted. ${ }^{72}$

Upon passage, Senator Dodd addressed the Senate to explain that the main point of the PREA is to give the "FDA the clear authority to require that drugs be tested and formulated for children." "73 Like the BPCA, the PREA will sunset in $2007 .^{74}$

\section{THE ANTIDEPRESSANT STORY IS A MODEL FOR THE DEFICIENCIES IN THE CURRENT LEGISLATION}

Although the BPCA and the PREA provide for the identification of drugs that need to be tested in pediatric patients and offer protection for children entering clinical studies, they do not go far enough to address many other health and safety concerns. The controversy surrounding the use of antidepressant medication in pediatric patients offers a good case study to analyze the deficiencies in the current legislative scheme. As is often the case, it may be difficult to cover all areas ex ante when promulgating legislative and regulatory schemes. Over the past few years, tests of multiple antidepressant medications in pediatric patients revealed antidepressants either did not work, induced suicidal behavior, or caused withdrawal symptoms when the patient was taken off

$355 \mathrm{c}(\mathrm{a})(4)(\mathrm{B})$

Id. $\$ 355 \mathrm{c}(\mathrm{b})(1)$.

Id. $\S 355 \mathrm{c}(\mathrm{b})(2)(\mathrm{A})$.

Id. $\S 355 \mathrm{c}(\mathrm{b})(2)(\mathrm{B})$.

Id. $\$ \S 355 \mathrm{c}(\mathrm{b})(2)(\mathrm{B})(\mathrm{iii})(\mathrm{aa}),(\mathrm{bb}),(\mathrm{iv})$.

Id. $\S 355 \mathrm{c}(\mathrm{b})(2)(\mathrm{D})$.

149 CON. REC. S9811, S9818 (2003).

7421 U.S.C. $§ 355 a(n)$ (referring to amendment of 21 U.S.C. 351 et seq.). 
the drug. ${ }^{75}$ Indeed, reports surfaced that some drug manufacturers may have known about the ineffectiveness or even negative effects of antidepressants for years. $^{76}$ The FDA's authority to require pediatric testing may have brought some of the negative effects of antidepressant drug use in children to light, but the regulatory scheme was neither able to address anecdotal information effectively, follow-up on manufacturer's information in clinical studies, nor respond quickly to developments in sister organizations in other countries. Therefore, the antidepressant story can be used to highlight where the deficiencies in pediatric testing exist and mark a good starting point to broaden the FDA's regulatory authority to protect children.

\section{A. The Forest Laboratories Clinical Studies Demonstrate Conflicting Clinical Results}

In the spring of 2004, Forest Laboratories announced that its antidepressant drug, Lexapro, did not help depressed pediatric patients. ${ }^{77}$ Lexapro contains the same active ingredient as Celexa. ${ }^{78}$ The patent on Celexa is about to expire and it has been reported that perhaps Forest Laboratories is promoting Lexapro so as to make money during the patent exclusivity time period. ${ }^{79}$ In the wake of the Lexapro announcement, Forest Laboratories also addressed its inadequate disclosure of a failed unpublished study in 2002 regarding use of Celexa in children. Only now, Forest Laboratories stated that a more recent 2004 test indicates Celexa may indeed help children. The results of the study, which was conducted in Europe from 1996 to 2002, showed Celexa had no greater effects than a placebo. ${ }^{80}$ That study, however, was published in a Danish textbook and therefore received little attention. ${ }^{81}$ Two of the outside researchers involved in the positive study on Celexa stated they did not know

75 Barry Meier, Drug Maker Acknowledges Some Negative Test Results, N.Y. TrMES, June 26, 2004, at C3 [hereinafter Meier, Negative Test Results]; Groopman, supra note 1, at 356.

76 Meier, Negative Test Results, supra note 75 (stating that Forest officials had not told a medical journal about a failed unpublished study in 2002 regarding the use of Celexa in children and adolescents prior to the medical journal's publication of an article about a separate test indicating the drug could help young people. Further, some of the authors of this article were Forest employees.).

77 Id. ("Forest Laboratories has said a recently concluded test found that its antidepressant Lexapro did not help depressed children and adolescents, an announcement that comes amid the growing controversy over clinical drug tests.").

78 Id.

79 Id.

80 Id.

81 Id. ("The European study was sponsored by H. Lundbeck, the Danish company that developed citalopram, which Forest markets in this country as Celexa."). The basic finding of that study, which reported that Celexa "showed no effects greater than a placebo-was noted in a chart published" in October 2003 in a medical textbook written in Danish. Id. 
about the results of the earlier study. ${ }^{82}$

The Lexapro and Celexa clinical studies raise a number of concerns. First, Forest Laboratories has not explained the discrepancies between the earlier study of Celexa that found no greater effect than a placebo and the more recent study that concluded the drug could help pediatric patients. Second, it is disconcerting that previous tests regarding the efficacy of Celexa in pediatric patients were not disclosed in a major medical or pharmaceutical journal or to the FDA. Third, the results of the Lexapro study showing that Lexapro did not help depressed pediatric patients is inconsistent with the recent positive results in the Celexa study because they contain essentially the same active ingredient. Perhaps other factors in the design of the clinical study contributed to the differences in the results. This suggests a more comprehensive scheme is needed to regulate the design of pediatric trials. The FDA appears inept at addressing the information obtained from these clinical trials.

\section{B. Anecdotal Reports Regarding Selective Serotonin Re-Uptake Inhibitors Caused the British Medical Health Regulatory Agency to Ban the Use of This Class of Antidepressant Drugs in Children}

Another class of antidepressant drugs, selective serotonin re-uptake inhibitors ("SSRIs"), has caused negative effects in pediatric patients. In the late 1980s, the British Medical Health Regulatory Agency ("BMHRA"), which is the British counterpart to the FDA, began monitoring reports of suicidal behavior and withdrawal symptoms among minors. ${ }^{83}$ The British government issued warnings in 1993 and $2000 .^{84}$ In June 2003, the BMHRA convened an emergency meeting and concluded the drug should not be used for pediatric patients. ${ }^{85}$ The United States followed suit ten months later and banned doctors from prescribing Paxil to children. ${ }^{86}$ This ten-month delay prompted, in part, a congressional investigation into the FDA with respect to pediatric testing. ${ }^{87}$

The situation with Paxil raises additional concerns. First, why did it take

82 Id. Two outside researchers involved in the positive Celexa study also said in recent interviews that Forest did not tell them about the efficacy findings of the European study and that they were not independently aware of them. Id.

83 Groopman, supra note 1, at 35 ("In the late nineteen-eighties, Britain's medical regulatory agency began closely monitoring anecdotal reports of suicidal behavior and withdrawal symptoms related to one class of antidepressants ....").

84 Id.

85 Id. ("In June, 2003, the agency convened an emergency meeting to review pediatric trial data on Seroxat, and S.S.R.I. known in the United States as Paxil, and concluded that the drug should not be prescribed for minors.").

${ }^{86}$ Id. ("Ten more months passed before the F.D.A. took similar action on children and antidepressants.").

87 Publication and Disclosure Issues in Antidepressant Pediatric Clinical Trials: Hearing Before the Subcomm. on Oversight and Investigations of the H. Comm. on Energy and Commerce, 108th Cong. (2004) [hereinafter Hearing on Antidepressant Pediatric Trials] (statement of U.S. Rep. Greg Walden of Oregon). 
over ten years of anecdotal reports suggesting serious negative consequences before the United States decided to ban the use of Paxil in pediatric populations? This suggests the FDA does not collect and react to anecdotal reporting effectively. The PREA is a good start to grant the FDA authority to require clinical trials for drugs used in pediatric populations. The FDA, however, must be capable of responding on various fronts in addition to requiring pediatric studies. Second, why did the United States take ten months to ban pediatric prescriptions after the BMHRA concluded its emergency study? The FDA should have the capability to combine resources with its sister organizations in other countries. Third, why does the FDA appear to have such a difficult time determining drug safety in pediatric patients?

\section{The Eli Lilly Clinical Studies Showed that the FDA and Researchers Must be Attentive When Taking Adolescents Off Antidepressants}

Eli Lilly recently made headlines when Traci Johnson, a college student, committed suicide after being switched to a placebo in a clinical trial of Cymbalta. ${ }^{88}$ The severe depression, leading ultimately to suicide, was believed to be caused by "hallucinations and paranoid delusions [that] can occur when a patient is withdrawn from an antidepressant." cleared of all wrongdoing, this experience begs at least two questions: (1) what were the deficiencies in the clinical design of the Cymbalta trial, if any, and (2) how can the FDA ensure this tragedy will not be repeated? The Cymbalta study indicates that children may still be undergoing developmental changes until their late teens or early twenties. The FDA should consider redefining their pediatric age groups to include college-age students. ${ }^{90}$

The BPCA allows for the IOM to oversee many of the ethical concerns regarding pediatric research and to coordinate with Institutional Review Boards ("IRBs"). Although this is a good move toward addressing the ethical problems associated with pediatric research, it appears that anecdotal reporting of withdrawal symptoms may not have been incorporated into pediatric trials. The policy recommendations described in Part $\mathrm{V}$ may allow a larger breadth of information for the FDA, the IOM, and the IRBs to use when establishing and conducting pediatric trials.

\section{Committee Hearings Addressed Antidepressant Clinical Studies in Pediatric Populations}

In 2004, committee hearings commenced to address pediatric trials, and

88 Groopman, supra note 1 , at 35.

89 Id. at 34 (describing the Cymbalta study and stating the FDA cleared Eli Lilly of wrongdoing).

$90 C f$. Rodriguez, supra note 45 (identifying pediatric age groups up through age sixteen). 
the house representatives learned the FDA knew that twelve of fifteen pediatric trials of antidepressant drugs proved that the drugs were ineffective. ${ }^{91}$ Moreover, only three of the fifteen studies were published. ${ }^{92}$ Representative Joe Barton of Texas stated,

[M] any people want to know what was in the other 12 studies? What do these studies show? Why haven't those other 12 studies been published in peer reviewed journals? Was there sufficient information available to the public about these unpublished studies to make informed decisions ${ }^{93}$

The committee hearing focused on the problems of disclosure in clinical trials. One proposed bill would require manufacturers and researchers to register with an online database as a prerequisite for IRB approval. ${ }^{94}$ This database would then include the results of all clinical trials whether positive, inconclusive, or negative. The proposed bill would give the FDA authority to require this registration and noncompliance would be enforced through civil penalties. ${ }^{95}$ The reporting system would give clinicians all the relevant information needed to make informed decisions. ${ }^{96}$

In addition, the committee noted that only one antidepressant medication, Prozac, is approved for treating depression in children. ${ }^{97}$ Four other drugs, however, are prescribed to children with depression in greater frequency than Prozac. ${ }^{98}$ This is particularly troubling because studies suggest that children taking some antidepressants are 1.89 times more likely to have suicidal thoughts than those given a placebo. ${ }^{99}$ This highlights the importance of conducting clinical trials for all antidepressant medications used to treat childhood depression and establishing post-market-approval surveillance to determine whether additional side effects are present.

91 Hearing on Antidepressant Pediatric Trials, supra note 87, at 30 (statement of U.S. Rep. Greg Walden of Oregon).

92 Id. at 1 (statement of U.S. Rep. Joe Barton of Texas, Chairman, Subcomm. on Oversight and Investigations).

93 Id. (statement of U.S. Rep. Joe Barton of Texas, Chairman, Subcomm. on Oversight and Investigations).

94 Id. at 13 (statement of U.S. Rep. Edward Markey of Massachusetts).

95 Id. (statement of U.S. Rep. Edward Markey of Massachusetts).

96 Id. (statement of U.S. Rep. Edward Markey of Massachusetts).

97 Id. at 39 (statement of Janet Woodcock, FDA Deputy Commissioner of Operations).

98 Id. at 218 (statement of U.S. Rep. Greg Walden of Oregon, Vice Chairman, Subcomm. on Oversight and Investigations).

99 Id. at 7 (statement of U.S. Rep. Greg Walden of Oregon, Vice Chairman, Subcomm. on Oversight and Investigations). 


\section{POLICY RECOMMENDATIONS TO ADDRESS THE DIFFICULTIES ASSOCIATED WITH PEDIATRIC STUDIES}

Pediatric clinical studies are needed to determine safe and effective doses in children. The protocol of "dosing down" adult prescriptions to account for the smaller size of children does not address physiological differences between adults and children. Medications that may be safe for use in adults could be quite unsafe in children. Children should not be put at risk when a comprehensive program can be instituted to address their particularities. Although the FDAMA, BPCA, and PREA are good starting points with their particular emphasis on the treatment of children engaged in a clinical trial, specific changes and further regulation are needed to protect pediatric patients.

As the FDA comes under increased scrutiny following the wake of the antidepressants and Vioxx ${ }^{100}$ scandals, the time is ripe to address obvious and notable deficiencies in the current regulatory scheme. Moreover, because the Act will sunset in 2007, new policy changes need to be implemented. A variety of policy recommendations should be considered as both Congress and the FDA move forward to meet these challenges. Policy suggestions include the following: (1) listing the trials of drugs in public databases and including reports of inconclusive or negative clinical trials, (2) changing the exclusivity provision, (3) labeling changes, and (4) implementing effective post-approval surveillance mechanisms.

\section{A. Public Databases That Disclose Medical Device and Drug Tests by Reporting Inconclusive or Negative Clinical Trials}

The FDA should establish a public database that lists all drugs, clinical trials, and results of the clinical trials. The American Medical Association ("AMA") and other medical groups are placing pressure on the FDA to establish a database where clinical trials can be tracked from beginning to end. ${ }^{101}$ In addition, some medical journals are contemplating requiring manufacturers to

100 See Gina Kolata, Merck and Vioxx: The Overview, N.Y. TIMES, Oct. 1, 2004, at A1; Gardiner Harris, Drug-Safety Reviewer Says F.D.A. Delayed Vioxx Study, N.Y. Times, Nov. 4, 2004, at A21; Anna Wilde Mathews \& Barbara Martinez, Warning Signs: E-Mails Suggest Merck Knew Vioxx's Dangers at Early Stage; As Heart-Risk Evidence Rose, Officials Played Hardball; Internal Message: 'Dodge!'; Company Says 'Out of Context,' Wall St. J., Nov. 1, 2004, at A1; Eric J. Topol, Failing the Pubic Health-Rofecoxib, Merck, and the FDA, $351 \mathrm{~N}$. ENG. J. MED. 1707, 1707-09 (2004).

101 See Meier, Negative Test Results, supra note 75 ("The American Medical Association has called on the federal government to create a database in which trials can be tracked from start to finish."); see also Barry Meier, Medicine's Data Gap: When Labels Mislead; Results of Drug Trials Can Mystify Doctors Through Omission, N.Y. TIMES, July 21, 2004, at C1 ("In recent weeks, the academy and other medical groups have met with lawmakers to discuss possible legislation requiring companies to list tests of drugs and medical devices in a public database."). 
register their clinical trials with the journal as a prerequisite to publication. ${ }^{102}$ Although this type of policy reform could be applied to the FDA as a whole, perhaps a smaller sample size that is focused on pediatric trials will allow the FDA to learn how to manage this type of public database before expanding it to every clinical trial.

To date, if a pharmaceutical company performs a clinical study in which the results show the drug is not helpful for a particular condition, then the clinical study is often not published. For example, if a manufacturer conducts a clinical trial to determine whether its FDA-approved drug for headaches may also be beneficial for muscle aches, but the results of the study show that the drug is not clinically helpful for muscle aches, then the study may not be reported. In this example, no negative side effects are reported, so it may not cause a public health hazard. Although it may not harm a person to take the headache medicine for a muscle ache, would it not be helpful for that person to at least know that the test has been conducted?

What if the pharmaceutical company learned in its study that its FDAapproved drug indeed causes muscle aches? Is the pharmaceutical company now required to publish the results of the negative study? To date, the pharmaceutical company must make the results of its study known to the FDA, but neither the pharmaceutical company nor the FDA seems to disseminate the results. ${ }^{103}$ In addition to labeling requirements, pharmaceutical companies should be required to publish the results of clinical studies that have negative clinical results on a particular patient population in a public database.

In addition to the failure to report negative or inconclusive clinical trials, a recent study suggests that a publication bias exists for studies funded by pharmaceutical companies. ${ }^{104}$ It appears that journals are more likely to a publish research supported by drug companies compared with clinical trials unsupported by drug companies. ${ }^{105}$ If this is true, then a public database of all clinical trials and their results should be available to the public. This will allow physicians to receive unfiltered information and then narrow their drug choice when prescribing medications to patients.

The Lexapro and Celexa clinical studies illustrate the importance of this type of information dissemination. A mandatory database that publishes all clinical trials and their results would provide a full picture to the medical com-

102 Meier, Negative Test Results, supra note 75 (“'And several medical journals are considering a proposal that would require trials to be registered at the outset as a prerequisite to the results' eventual publication.").

103 Hearing on Antidepressant Pediatric Trials, supra note 87, at 8 (statement of U.S. Rep. Henry Waxman of California) ("They are making it known to the FDA because they have to, and we want to ask why [the] FDA has not done more to get this information out, but there is a clear responsibility for the companies ....").

104 John Yaphe, Richard Edman, Barry Knishkowy \& Joseph Herman, The Association Between Funding by Commercial Interests and Study Outcome in Randomized Controlled Drug Trials, 18 FAM. PRAC. 565, 567 (2001) (discussing the results of their publication bias study). 105 Id. 
munity. ${ }^{106}$ It would most likely be cumbersome and difficult to parse through the information if each phase of the pediatric trials were recorded in the database. Therefore, each Phase III trial should be registered in the database and include background information regarding the earlier phases. If, however, the drug never makes it past a Phase I trial for either safety or efficacy reasons, then this information should be uploaded to the database and also indicated on the label.

In this way, public disclosure of all registered clinical trials will include positive, inconclusive, and negative results. For example, this type of information dissemination of antidepressant medication trials could have impacted the medications physicians prescribed to their patients. Indeed, pediatric trials of many of the drugs believed to cause suicidal thoughts were conducted, but the results of these studies were not widely available. If the antidepressants either did not help pediatric patients or worse yet caused negative side effects, this information should be made public. Under the current regulatory scheme, these studies are not required to be published. A federal registry of these test results, compiled by the FDA, could alleviate this problem.

Opponents to the required public disclosure of the results of all clinical trials might argue against heightened regulatory schemes. They might argue that increased regulatory measures in one area might lead to increased regulatory measures in other areas. For example, the FDA might begin to regulate a physician's ability to prescribe drugs "off-label." This is unlikely, however, because off-label use of drugs is an accepted practice and even defined in the regulations. $^{107}$

Opponents may also argue that the drug industry will set up a public registry voluntarily, thus obviating the need for legislation. ${ }^{108}$ In light of the unreported Forest Laboratories studies described earlier, a clear requirement to report pediatric trials appears necessary to address inconclusive and negative results. Regulations aimed at full disclosure of clinical trials are needed to fully inform the medical community.

\section{B. Changes Should Be Made to the Exclusivity Provision}

When the BPCA was first passed, debate surrounded the voluntary incen-

106 Hearing on Antidepressant Pediatric Trials, supra note 87, at 35 (statement of U.S. Rep. Henry Waxman of California) (discussing a new bill that would establish a registry of information about all the studies performed that would include positive, negative, and inconclusive studies).

107 Legal Status of Approved Labeling for Prescription Drugs; Prescribing for Uses Unapproved by the Food and Drug Administration, 37 Fed. Reg. 16,503, 16,503-04 (Aug. 15, 1972) (to be codified at 21 C.F.R. pt. 130); see Breslow, supra note 22, at 145 (discussing offlabel practice).

${ }^{108}$ Hearing on Antidepressant Pediatric Trials, supra note 87, at 36 (statement of U.S. Rep. Henry Waxman of California) (stating that Congress is going to hear that drug companies are willing to set up a registry voluntarily). 
tive structure for pediatric testing. Proponents argued that this legislative action, including the exclusionary provision, provides important incentives to pharmaceutical companies resulting in pediatric testing. ${ }^{109}$ Other supporters like the voluntary structure because they favor the incentive process over mandatory pediatric testing. ${ }^{110}$ As discussed below, to date, as long as the manufacturer conducts the studies and submits the results to the FDA, the manufacturer receives the market exclusivity extension. That is, even if the results of the studies are negative, the manufacturer will be granted the six-month patent extension.

Opponents of the voluntary incentive structure argued that some pediatric testing should be mandatory. ${ }^{11}$ Moreover, the exclusivity provision costs consumers enormous amounts of money in subsidizing the research because the cost of the trials and exclusionary period are passed along to the consumer. ${ }^{112}$ First, a manufacturer may raise the price of a drug to pay for the clinical trials. Second, consumers have access only to the one drug during the six-month exclusivity period even if the results of the pediatric trial are negative. Hence, the consumers pay on both ends for the clinical studies. In some situations where the manufacturer does not conduct a required pediatric trial for already approved drugs, tax money may be used to conduct the study. Therefore, it costs the citizen money either as a consumer or as a taxpayer.

The PREA addressed the opponents' concerns to some extent, but it did not go far enough. The PREA recognized the exclusivity provision in the BPCA, but it changed the voluntary incentive structure. As described in Part III, the FDA established a list of drugs requiring pediatric testing. ${ }^{113}$ For FDAapproved drugs, the FDA gave an option to the manufacturer to test the drug. If the manufacturer did not want to test the drug, then the FDA could contract with a third party to conduct the test. ${ }^{114}$ For new drugs, the FDA could require pharmaceutical companies to either conduct a pediatric clinical trial or apply for a waiver. The revision in the PREA, however, did not address the cost to the consumer and taxpayer.

As policy considerations, the patent extension should be conditioned on the following two criteria. First, the drug must be shown to be safe and effective in the approved pediatric trials. That is, the exclusivity provision should apply only to drugs that will be approved for use in pediatric populations. To date, if a manufacturer conducts a pediatric trial, but the drug is shown to be

109 Breslow, supra note 22, at 182-83 (citing congressional records regarding the BPCA).

110 Id. at 183 (noting proponents' positions).

111 Id. (citing congressional records regarding the BPCA).

112 Id. at 183,189 (discussing costs passed onto the consumer directly or indirectly).

113 Program for Pediatric Studies of Drugs, 42 U.S.C. $\$ 284 \mathrm{~m}$ (a)(1) (Supp. III 2003); List of Drugs for which Additional Pediatric Information may Produce Health benefits in the Pediatric Population, 63 Fed. Reg. 27,733, 27,734 (May 20, 1998).

11442 U.S.C. $\$ 284 \mathrm{~m}(\mathrm{~b})-(\mathrm{c})$. 
unsafe or ineffective, the manufacturer still receives the market exclusion. ${ }^{115}$ Opponents of this idea may argue that the high cost of clinical trials will create disincentives for manufacturers to conduct the trials without the guarantee of receiving the market exclusion. This is because the manufacturers become familiar with the six-month extension. If, however, the market extension was changed to an "icing on the cake" benefit for the required testing, then manufacturers would be required to conduct the trials and receive a benefit only if the drug is safe and effective in pediatric populations. Thus, consumers will bear the cost only for drugs that will be used in pediatric populations and not for all drugs tested on children. For new drug applications, the six-month market exclusion could be tacked on to the patent extension granted under the Hatch-Waxman Act.

Second, the patent extension should occur only after the label changes are fully implemented. ${ }^{116}$ As described below, the average time for a label change is five months, and in some cases it occurs after one year. ${ }^{117}$ Physicians need to know how to appropriately prescribe medications to pediatric populations, and the patent extension should not begin until the appropriate label changes are made.

\section{The New Policy Should Address Labeling Changes}

The results of all pediatric clinical trials should follow a more rigid time frame. The antidepressant cases highlight the importance of disseminating all known information to physicians so they can prescribe the correct drug to their patients. The BPCA strengthened labeling requirements, but it did not mandate proper labeling of drugs before marketing. ${ }^{118}$

In 1979 , the FDA changed the labeling requirements to include a pediatric use subsection. ${ }^{119}$ Under this rule, if a manufacturer completed pediatric trials and the drugs were approved for use in pediatric populations, then both the indication and dose would be described under the appropriate labeling sections. If a drug had not been tested for use in children, then the label reflected that by saying either "safety and effectiveness in pediatric patients below the age of

${ }^{115}$ Hearing on Antidepressant Pediatric Trials, supra note 87, at 17 (statement of U.S. Rep. Bart Stupack of Michigan).

${ }_{116} I d$. ("We have it backwards. The patent extension should only occur if the drug is safe, effective and after the necessary label changes are fully implemented. Then, and only then, should a patent extension be granted."). Michigan).

117149 CONG. REC. H11567, H11571 (2003) (statement of U.S. Rep. Bart Stupack of

118 Id. ("As we said earlier, the Best Pharmaceutical Act of 2002 did require a strengthening of labeling requirements, but it did not mandate proper labeling before marketing of these drugs.").

11921 C.F.R. $\S \S 201-202$ (2002); see Labson, supra note 39, at 39-41 (describing the labeling requirements). 
$($ ) have not been established"120 or "safety and effectiveness in pediatric patients have not been established."

The PREA does not contain a provision addressing proper use and labeling prior to marketing and use in children. During the congressional hearings for the passage of the PREA, Representative Bart Stupack of Michigan stated:

So before a drug is marketed, it should be properly labeled with all the necessary information to be used in pediatric patients. Doctors and patients and families have no idea on how to administer drugs or what the effect will be on young people without proper labeling. All I am saying is we should have had an opportunity to amend this legislation to make sure before a patent is extended, before a drug is given for pediatric patients, that the proper labeling is done and made available to doctors, patients, and their families. It is marketed and given to children before we know what the effects are on young people. $^{122}$

One of the main reasons for the need for pediatric testing is that physicians were "dosing down" prescriptions for children based on body weight. ${ }^{123}$ But "dosing down" from a whole tablet to a half a tablet, for example, may not be the appropriate dosage - or even a safe medication - for a child. Indeed, the reason for this is that children are still developing and may have different biochemical reactions to any particular drug, whether it is a full dose or a partial dose, and "dosing down" may be ineffective or potentially harmful. A pediatric clinical trial should determine both the safety of the drug and the optimal dose and these should be reflected on the label so a physician can prescribe a drug correctly. To address this problem, a stricter time frame for safe and effective drugs should be implemented to comply with labeling requirements.

Moreover, if the results of a clinical trial are inconclusive or negative, the labeling changes should reflect these results immediately. For example, if a clinical trial is conducted for an antidepressant drug and the results show the drug is safe but not effective, the label should reflect this result. ${ }^{124}$ The label

120 Specific Requirements on Content and Format of Labeling for Human Prescription Drugs, 21 C.F.R. $\$ 201.57(f)(9)(v)$ (2002); see Labson, supra note 39, at 40.

12121 C.F.R. $\S 201.57(f)(9)(v i)$; see Labson, supra note 39, at 40.

122149 CONG. REC. H11567, H11571 (2003) (statement of U.S. Rep. Bart Stupack of Michigan).

123 Groopman, supra note 1.

124 Hearing on Antidepressant Pediatric Trials, supra note 87, at 17 (statement of U.S. Rep. Bart Stupack of Michigan) ("Remember, each patent extension often means hundreds of millions of dollars to the drug companies. This systematic flaw that rewards companies for doing a study, the results of which are not made public, which may show the drug is not effective and actually may harm young people and the consumers' notice, the package labeling is not immediately changed.") 
could say; "the results of a clinical trial show that this drug may be safe, but not effective, for use in pediatric populations." In this way, the physician is educated about the drug's potential benefits or lack thereof. This will give pharmaceutical companies an incentive to conduct additional clinical trials to determine effectiveness and thereby use in pediatric populations. Alternatively, pharmaceutical companies may not want to conduct pediatric trials due to their high cost and the possibility of negative results. But, if the FDA determines that the drug is important for use in children, then the drug company may be required to conduct the tests.

\section{The FDA Should Implement Additional Post-Approval Surveillance Mechanisms}

The FDA can approve the use of a drug for children based on the results of a pediatric clinical trial, but the clinical trials may not cover all age groups or reveal long-term side effects. One of the biggest challenges in evaluating pediatric populations is the biological immaturity of organs. Adolescents may have very different biological reactions than toddlers. In addition, finding large sample sizes of children in a variety of age ranges makes conducting clinical trials across an eighteen-plus year age span extremely challenging. Thus, postapproval surveillance in pediatric populations will be a critical source of safety and efficacy information.

The PREA is a step in the right direction for follow-up studies in pediatric populations; however, it still suffers from some of the same flaws seen in the complete FDA post-approval regulatory scheme. First, MedWatch is a voluntary reporting system that allows physicians to report anecdotal information about a particular drug. ${ }^{125}$ MedWatch is a passive system for physician reporting, and it is unclear whether it provides the appropriate breadth of information for the FDA to determine the potentially deleterious safety and efficacy problems of approved drugs. ${ }^{126}$ Second, the FDA suffers from an internal structural dilemma. The Center for Drug Evaluation and Research ("CDER") is the part of the agency responsible for drug approval. Sitting below the CDER is the Office of Drug Safety. Once the CDER approves a drug, some hypothesize that tension exists, based on the hierarchy, and it may be difficult for the Office of Drug Safety to invalidate the previous approval. ${ }^{127}$ Finally, the drug companies

125 See U.S. Dep't Health \& Human Servs., MedWatch: The FDA Safety Information and Adverse Event Reporting Program, Form FDA 3500 (Oct. 2005) available at $\mathrm{http} / / / \mathrm{www} . \mathrm{fda} . \mathrm{gov} / \mathrm{medwatch} / \mathrm{safety} / 3500$.pdf (form used to voluntarily report adverse events and product problems under the MedWatch program).

126 Phil B. Fontanarosa, Drummond Rennie \& Catherine D. DeAngelis, Postmarketing Surveillance - Lack of Vigilance, Lack of Trust, 292 J. AM. MED. Ass'N 2647, 2647, 2649 (2004) (describing MedWatch as a passive collection system); see also Groopman, supra note 1, at 35-6.

${ }_{127}$ Richard Horton, Vioxx, The Implosion of Merck, and Aftershocks at the FDA, 364 THE LANCET 1995, 1995 (2004) (describing the inherent flaws in the FDA regulatory scheme). 
have little incentive to conduct and report clinical trials that would show adverse drug reactions. In order to protect their economic interests, drug companies may either not conduct additional clinical trials or use subversive tactics to cover up negative information. ${ }^{128}$

The specific pediatric problems must be addressed by the FDA. Specifically, the FDA should establish a post-approval surveillance mechanism that requires additional pediatric testing, follows anecdotal information, and uses information gathered from similar agencies in other countries. As suggested for the FDA in general, an independent body should exist to regulate and monitor post-approval safety and efficacy of drugs. ${ }^{129}$ Due to the recognized niche of pediatric populations, an independent "Pediatric Post-Approval Surveillance Safety and Efficacy Office" should be established.

This new office could address many of the problems described above. ${ }^{130}$ First, it could specifically enforce post-approval clinical trials needed for additional age groups or population sizes, and Congress could grant the new office the ability to bring legal sanctions against manufacturers who fail to comply with the mandatory post-approval testing. ${ }^{131}$ Second, the office could evaluate whether the voluntary MedWatch system is an effective means to monitor postapproval adverse drug effects. The agency could also give the MedWatch program a "face-lift" to allow it to effectively follow anecdotal information. Finally, the new office could collaborate more closely with its sister organizations in other countries. Under this approach, the FDA may have reacted faster to the needed ban on SSRIs prescribed to pediatric populations.

\section{CONCLUSION}

The testing of drugs in pediatric populations runs along a regulation continuum. First, drugs that will be used in pediatric populations must be identified. Second, carefully planned and ethical clinical trials must be conducted. Finally, post-approval surveillance systems should monitor additional information learned about a particular drug.

The current regulatory and legislative schemes address only parts of the continuum for safe and effective drug use in pediatric populations. New policy changes must be implemented to remedy the identified deficiencies.

The policy suggestions described above incorporate suggestions made by others and offer important improvements. First, the dissemination of information through public databases will provide the medical community with impor-

128 Fontanarosa, Rennie \& DeAngelis, supra note 126, at 2649 (noting the industry's forprofit motivations).

129 Id. (discussing the establishment of an independent agency for drug safety).

${ }^{130} \mathrm{Id}$. at 2649-50 (proposing the establishment of an independent agency "to oversee postmarketing surveillance for drugs and devices" and referencing other people's suggestions for a surveillance system).

${ }^{131} I d$. (discussing post-marketing studies and legal penalties). 
tant information when prescribing drugs to their patients. It will also hold the manufacturers accountable for supplying the public with the results of their trials. Second, the market exclusivity provision should only apply to drugs that are shown to be safe and effective in pediatric populations. Third, stricter time frames for labeling changes should occur with the results of pediatric trials to provide physicians and patients with reliable information. Finally, to address the post-approval surveillance problems, Congress could grant the FDA the authority to establish an independent office to monitor safe and effective drug use in pediatric populations, evaluate the effectiveness of the voluntary MedWatch system, assess the current pediatric age group guidelines, and work closely to share information with sister organizations in other countries.

A great many lessons are learned from evaluating the deficiencies in the FDAMA, BPCA, and PREA. Due to the special nature of pediatric populations, they require heightened regulatory measures to provide them with safe and effective drugs. Because the BPCA and the PREA will sunset in 2007, many of the regulatory deficiencies can be addressed with new legislation and regulatory schemes. 